\title{
Scintigraphic Investigations of the Lymphatic System: The Influence of Injected Volume and Quantity of Labeled Colloidal Tracer
}

\author{
Pierre Bourgeois \\ Service of Nuclear Medicine, Institut Jules Bordet, Université Libre de Bruxelles, Brussels, Belgium
}

Volumes injected for lymphoscintigraphic investigations are highly variable, and the quantity of labeled colloids injected is usually not reported. The aim of the present study was to evaluate whether and how volume and quantity quantitatively affect lymphoscintigraphic results. Methods: Each of 9 healthy volunteers ( 4 men and 5 women; mean age, 21 y; range, 19-26y) participated in 4 lymphoscintigraphic investigations using the same protocol, in which the volume injected was 0.2 or $1.0 \mathrm{~mL}$ and the quantity injected was 0.02 or $0.2 \mathrm{mg}$. Subcutaneous injections of $99 \mathrm{mTc}-$ labeled human serum albumin nanosized colloids were placed in the first interdigital space of each foot. Activity at the injection sites and in the inguinoiliac nodes after a standardized sequence of rest, exercise, and normal-activity periods was measured and analyzed as a function of volume and quantity. Results: The highest extraction rate was observed for a quantity of $0.2 \mathrm{mg}$ and a volume of $0.2 \mathrm{~mL}$. This extraction rate was significantly higher than the rates obtained for a quantity of $0.2 \mathrm{mg}$ and a volume of $1.0 \mathrm{~mL}$ or for a quantity of $0.02 \mathrm{mg}$ and a volume of $0.2 \mathrm{~mL}$, neither of which differed from the extraction rate for a quantity of $0.02 \mathrm{mg}$ and a volume of $1.0 \mathrm{~mL}$. Activity in inguinoiliac nodes was significantly higher for a quantity of $0.2 \mathrm{mg}$ than for a quantity of $0.02 \mathrm{mg}$, irrespective of volume. With quantity remaining constant, volume did not influence the activity in inguinoiliac nodes. Conclusion: Both volume and quantity influence the results of lymphoscintigraphic investigations with regard to the quantities extracted from injection sites and the accumulations in nodal regions. Therefore, volume and quantity should be standardized when quantitative parameters are used for diagnostic purposes.

Key Words: lymphoscintigraphy; volume; concentration; colloidal albumin

J Nucl Med 2007; 48:693-695

DOI: 10.2967/jnumed.107.039594

$\mathbf{L}$ ymphoscintigraphy using ${ }^{99 \mathrm{~m}} \mathrm{Tc}$-labeled colloids is a simple and nontraumatic method for studying diseases of the lymphatic system. The technique has been used to evaluate lymph nodes in various types of cancer $(1,2)$. It is now used

Received Aug. 11, 2006; revision accepted Feb. 12, 2007.

For correspondence contact: Pierre Bourgeois, MD, PhD, Service of Nuclear Medicine, Institut Jules Bordet, Université Libre de Bruxelles, 121, Boulevarde de Waterloo, B-1000, Brussels, Belgium.

E-mail: pierre.bourgeois@bordet.be

COPYRIGHT @ 2007 by the Society of Nuclear Medicine, Inc. merely to demonstrate so-called sentinel lymph nodes $(3,4)$ and is also applied in assessing limb edemas (5-12). In publications devoted to these oncologic and nononcologic lymphoscintigraphic investigations, highly variable volumes have been injected, and the quantity of injected colloids has rarely been mentioned. Nonetheless, each of these parameters can influence the results of investigations, both qualitatively (nodal visibility) and quantitatively (nodal activity levels or extraction of tracer from injected sites). The present study was undertaken to determine the influence of volume and quantity on quantitative parameters of lymphoscintigraphy.

\section{MATERIALS AND METHODS}

Nine healthy volunteers (4 men and 5 women; mean age, 21 y; range, 19-26 y) participated. The subjects had no history of upperlimb osteoarticular or lymphatic lesions. Subjects who were likely to have lesions of the lymphatic system (with diseases such as psoriasis or diabetes or who regularly played sports such as soccer, basketball, or volleyball) were also excluded from the study.

Each volunteer underwent an identical protocol of 4 lymphoscintigraphic investigations with a minimum of $2 \mathrm{~d}$ between each.

The study protocol was approved by the institutional ethics commission, and all volunteers provided written informed consent to participate.

${ }^{99 m}$ Tc-Labeled human serum albumin nanosized colloids (Nanocoll; Amersham) (vials from the same kit were used for each subject) were injected subcutaneously into the first interdigital space of the right and left feet, with the subjects having been lying at rest for at least $5 \mathrm{~min}$. The mean radioactivity per injection was $17 \mathrm{MBq}$. Each injection was made by the same experienced physician using a tuberculin syringe in a way that avoided an intravenous injection.

Volume and quantity were modified for each of the 4 procedures according to the following schedule: for the first procedure, volume was $0.2 \mathrm{~mL}$ and quantity was $0.2 \mathrm{mg}$; for the second, volume was 0.2 $\mathrm{mL}$ and quantity was $0.02 \mathrm{mg}$; for the third, volume was $1.0 \mathrm{~mL}$ and quantity was $0.2 \mathrm{mg}$; and for the fourth, volume was $1.0 \mathrm{~mL}$ and quantity was $0.02 \mathrm{mg}$. Activity was recorded (anterior views) using a single-head, single-photon $\gamma$-camera (SophyCam; Sopha) equipped with a parallel-hole, all-purpose, low-energy collimator, using the same geometry in each case with respect to the $\gamma$-camera field: at the injection site immediately after injections and at the end of the protocol (dynamic acquisition, 10-frame matrix of $64 \times 64 \times 16$ or word mode, $2 \mathrm{~s}$ each), and in the inguinoiliac region at the end of the 
protocol (static acquisition, frame matrix of $128 \times 128 \times 8$ or byte mode, $60 \mathrm{~s}$ each).

The protocol was standardized: After injections, the volunteers (still lying on the examination table) did not move their limbs, feet, or toes for the first $30 \mathrm{~min}$, after which they performed a tiptoeing exercise in unison for $5 \mathrm{~min}$. Finally, they stood up and walked for $30 \mathrm{~min}$.

We analyzed the extraction at the injection sites. Radioactivity at the end of the examination protocol was corrected for physical decay of ${ }^{99 \mathrm{~m}} \mathrm{Tc}$ and divided by radioactivity immediately after injection and was expressed as a percentage of radioactivity after injection. We also analyzed the nodal radioactivity. Radioactivity of the inguinoiliac node region was corrected for physical decay of ${ }^{99 \mathrm{~m}} \mathrm{Tc}$ and background radiation, normalized for acquisition parameters, and expressed as a percentage of radioactivity after injection. We compared the results for the 18 limbs using the Student paired $t$ test at a significance level of 0.05 .

\section{RESULTS}

Data on the extraction of labeled colloids as a function of injected volume or quantity are summarized in Table 1. For a volume of $1.0 \mathrm{~mL}$, the extraction rate for a quantity of $0.2 \mathrm{mg}$ did not differ significantly from that for a quantity of $0.02 \mathrm{mg}$, although it was slightly higher. For a volume of $0.2 \mathrm{~mL}$, the extraction rate was significantly greater for a quantity of $0.2 \mathrm{mg}$ than for a quantity of $0.02 \mathrm{mg}$. For a quantity of $0.2 \mathrm{mg}$, the extraction rate was significantly greater for a volume of $0.2 \mathrm{~mL}$ than for a volume of 1.0 $\mathrm{mL}$. For a quantity of $0.02 \mathrm{mg}$, the extraction rate did not significantly differ for different volumes.

Data on nodal radioactivity levels as a function of volume or quantity are summarized in Table 2. Volume did not influence nodal radioactivity levels when quantity remained constant. In other words, 5-fold dilutions of labeled tracer did not significantly modify colloidal activity in the nodes. When volume was constant, however, nodal radioactivity levels were significantly higher for a quantity of $0.2 \mathrm{mg}$ than for a quantity of $0.02 \mathrm{mg}$.

\section{DISCUSSION}

The 2 main conclusions of our work are that, regarding extraction and the effect of injected concentration of colloids,

TABLE 1

Extraction of Labeled Human Serum Albumin Nanosized Colloids as Function of Volume and Quantity of Protein Injected

\begin{tabular}{llll}
\hline & \multicolumn{3}{c}{ Quantity } \\
\cline { 2 - 4 } Volume & $0.2 \mathrm{mg}$ & $0.02 \mathrm{mg}$ \\
\hline $0.2 \mathrm{~mL}$ & $18.9 \pm 1.7$ & $2 P=0.01$ & $14.9 \pm 1.5$ \\
& $2 P=0.002$ & & $2 P>0.05$ \\
$1.0 \mathrm{~mL}$ & $14.0 \pm 1.1$ & $2 P>0.05$ & $10.8 \pm 1.9$ \\
& \\
\hline $2 P=2$-tailed $P$ value. \\
$\begin{array}{l}\text { Results (mean } \pm \mathrm{SD} \text { ) are percentage of activity injected at time of } \\
\text { injection. }\end{array}$
\end{tabular}

TABLE 2

Nodal Activity as Function of Volume and Quantity of Protein Injected

\begin{tabular}{lccc}
\hline & \multicolumn{3}{c}{ Quantity } \\
\cline { 2 - 4 } Volume & $0.2 \mathrm{mg}$ & $0.02 \mathrm{mg}$ \\
\hline $0.2 \mathrm{~mL}$ & $15.2 \pm 1.3$ & $2 P<0.001$ & $7.8 \pm 1.2$ \\
& $2 P>0.05$ & $2 P>0.05$ \\
$1.0 \mathrm{~mL}$ & $13.5 \pm 1.9$ & $2 P=0.01$ & $8.6 \pm 1.7$ \\
& & \\
\hline $2 P=2$-tailed $P$ value. & \\
Results (mean \pm SD) are percentage of activity injected.
\end{tabular}

$1.0 \mathrm{mg} / \mathrm{mL}$ is significantly better than either $0.2 \mathrm{mg} / \mathrm{mL}$ or 0.1 $\mathrm{mg} / \mathrm{mL}$, both of which are better but not significantly better than $0.02 \mathrm{mg} / \mathrm{mL}$, and, regarding lymph node radioactivity, increasing the volume of an injection does not affect the rate of accumulation in the lymph nodes. On the other hand, if volume is held constant, activity in lymph nodes is directly related to the number of molecules injected.

Our results have ramifications for clinical practice. Indeed, the results are important for all lymphatic system examinations whose conclusions are based on functional parameters and, therefore, principally for all examinations that investigate edemas of the limbs. In this field, few authors rely purely on morphologic data $(9,10)$. The sensitivity of morphologic criteria $(7,9,10,12)$ often appears to be inferior $(70 \%-80 \%)$ to that of isolated functional parameters $(90 \%$ or more) $(5,8)$. In practice, most protocols for examining edemas of the limbs take into account both morphologic data and different functional parameters $(6-8,11,12)$. In fact, our study showed that lymphatic extraction of tracer from the injection site $(8,12)$, or its subsequent nodal accumulation (8), can vary significantly from one examination to the next according to variations in the quantity of tracer injected. All lymphatic system studies that use any of those functional parameters as diagnostic criteria must clearly specify and standardize the injected volumes, colloid radioactivity levels, and quantities of labeled tracer. In fact, although the injected volumes are usually mentioned and are constant in the various referenced papers, the quantities of labeled tracer in the injections are rarely reported as having been standardized.

The issue of the volume injected in lymphoscintigraphic investigations has become especially relevant with the development of sentinel lymph node techniques in breast cancer by intramammary and peritumoral injections of radiolabeled colloids. Indeed, the proposed volumes for this technique are highly variable and range from 0.2 to $16.0 \mathrm{~mL}$ (3,13-23). Some authors are opposed to large volumes, advocating that such nonphysiologic perturbation (dispersion of the labeled colloids over a volume larger than the tumor-containing volume) may cause erroneous identification of a lymph node as the sentinel node (24). Other authors argue against that hypothesis (25) and favor larger volumes because they increase interstitial pressure, which in turn increases lymphatic flow (26). Regarding the question of 
volume, Krag et al. (27) have taken it into account as a factor that could influence the result of lymphoscintigraphic investigations, and they concluded that volumes greater than $8.0 \mathrm{~mL}$ are associated with higher rates $(100 \%)$ of technical success (in the detection of the sentinel lymph node) than are smaller volumes $(78.8 \%$ for $2.9 \mathrm{~mL}<$ volume $<8.0 \mathrm{~mL}$ and $55.8 \%$ for volume $<3.0 \mathrm{~mL}$ ). However, in addition to volume, other factors (activity injected, investigation after excisional biopsy, delay before operation, tracer used) were varied in that study and were associated with technical success. Therefore, the data do not allow one to ascertain or assess the true effect of volume. On the other hand, Berman et al. (28) compared $2.0 \mathrm{~mL}$ and $6.0 \mathrm{~mL}$ and reported good detection rates with both. Regarding lymph node radioactivity, our results, although obtained with volumes lower than those of Krag et al. and Berman et al., suggest that increasing the injection volume does not affect the resulting accumulation rates in the lymph nodes. Furthermore, our results favor injections containing the greatest possible quantity of labeled molecules, a factor that was not considered (or specified) in any of the previously mentioned studies.

\section{CONCLUSION}

With regard to reporting qualitative or quantitative results of lymphoscintigraphy, our data stress the importance of specifying not only the injection volumes and radioactivity levels used but also the quantity of labeled tracer in the injections and their standardization. In terms of extraction rate and, thereby, the rate at which tracer is transported to the lymph nodes, our results favor the use of low-volume injections containing the greatest possible quantity of tracer (as permitted by radiopharmaceutical preparation methods). In other words, one should use the highest concentration of tracer possible. Regarding lymph node radioactivity, our results favor injections containing the greatest possible quantity of labeled molecules. Finally, our results suggest that increasing the volume does not affect accumulation rates in lymph nodes.

\section{REFERENCES}

1. Bourgeois P. Lymphoscintigraphy in adult malignancy. In: Murray I, Provan C, Ell PJ, eds. Nuclear Medicine in Clinical Diagnosis and Treatment. 1st ed. Edinburgh, U.K.: Churchill Livingstone, 1994:699-705.

2. Ege GN. Lymphoscintigraphy in oncology. In: Henkin RE. Nuclear Medicine. St. Louis, MO: Mosby; 1996:1504-1523.

3. Krag D, Weaver D, Ashikaga T, et al. The sentinel node biopsy in breast cancer: a multicenter validation study. N Engl J Med. 1998;339:941-946.

4. Chan AD, Morton DL. Sentinel node detection in malignant melanoma in lymphatic metastasis and sentinel lymphadenectomy. In: Schlag PM, Veronesi U, eds. Recent Results in Cancer Research. Berlin, Germany: Springer Verlag; 2000;157:161-177.

5. Franco A, Comet M, Beani JC, Doucet J, Meaulle PY, Guidicelli H. La lymphoscintigraphie indirecte: son intérêt pour le diagnostic étiologique des oedèmes des membres inférieurs de cause non médicale. J Biophys et Med Nucl. 1980;4:299-303.

6. Pecking A, Firmin F, Rain JD, et al. Lymphoedema of the upper limb following surgery or radiotherapy: investigation by indirect radioactive lymphography. Nouv Presse Med. 1980;9:3349-3351.

7. Weissleder H, Weissleder R. Lymphedema: evaluation of qualitative and quantitative lymphoscintigraphy in 238 patients. Radiology. 1988;167:729-735.

8. Carena M, Campini R, Zelaschi G, Rossi G, Aprile C, Paroni G. Quantitative lymphoscintigraphy. Eur J Nucl Med. 1988;14:88-92.

9. Golueke PJ, Montgomery RA, Petronis JD, Minken SL, Perler BA, Williams GM. Lymphoscintigraphy to confirm the clinical diagnosis of lymphedema. J Vasc Surg. 1989;10:306-312.

10. Ter SE, Alavi A, Kim CK, Merli G. Lymphoscintigraphy: a reliable test for the diagnosis of lymphedema. Clin Nucl Med. 1993;18:646-654.

11. Cambria RA, Gloviczki P, Naessens JA, Wahner HW. Non invasive evaluation of the lymphatic system with lymphoscintigraphy: a prospective, semiquantitative analysis in 386 extremities. J Vasc Surg. 1993;18:773-782.

12. Bourgeois P, Munck D, Becker C, Leduc O, Leduc A. Re-evaluation of a threephase lymphoscintigraphic investigation protocol for the lower limb edemas. Eur J Lymphol Rel Probl. 1996;6:10-21.

13. Uren RF, Howman-Giles RB, Thompson JF, et al. Mammary lymphoscintigraphy in breast cancer. J Nucl Med. 1995;36:1775-1780.

14. De Cicco C, Chinol M, Paganelli G. Intraoperative localisation of the sentinel node in breast cancer: technical aspects of lymphoscintigraphic methods. Semin Surg Oncol. 1998;15:268-271.

15. De Cicco C, Cremonesi M, Luini A, et al. Lymphoscintigraphy and radioguided biopsy of the sentinel axillary node in breast cancer. J Nucl Med. 1998;39:20802084.

16. Rink T, Heuser T, Fitz H, Schroth HJ, Weller E, Zippel HH. Lymphoscintigraphic sentinel node imaging and gamma probe detection in breast cancer with 99mTc-nanocolloidal albumin: results of an optimized protocol. Clin Nucl Med. 2001;26:293-298.

17. Roumen RM, Valkenburg JG, Geuskens LM. Lymphoscintigraphy and feasibility of sentinel node biopsy in 83 patients with primary breast cancer. Eur J Surg Oncol. 1997;23:495-502.

18. Borgstein PJ, Pijpers R, Comans EF, Van Diest DJ, Boom RP, Meijer S. Sentinel lymph node biopsy in breast cancer: guidelines and pitfalls of lymphoscintigraphy and gamma probe detection. J Am Coll Surg. 1998;186:275-283.

19. O'Hea BJ, Hill AD, El-Shirbiny AM, et al. Sentinel lymph node biopsy in breast cancer: initial experience at Memorial Sloan-Kettering Cancer Center. J Am Coll Surg. 1998;186:423-427.

20. Van der Ent FW, Kengen RA, van der Pol HA, Hoofwijk AG. Sentinel node biopsy in 70 unselected patients with breast cancer: increased feasability by using $10 \mathrm{mCi}$ radiocolloid in combination with a blue dye tracer. Eur J Surg Oncol. 1999;25:24-29.

21. Bass SS, Dauway E, Mahatme A, et al. Lymphatic mapping with sentinel lymph node biopsy in patients with breast cancers $<1$ centimeter (T1A-T1B). Am Surg. 1999;65:857-861.

22. Haigh PI, Hansen NM, Giuliano AE, Edwards GK, Ye W, Glass EC. Factors affecting sentinel node localization during preoperative breast lymphoscintigraphy. J Nucl Med. 2000;41:1682-1688.

23. Schmidt MS, Gardner PM, Redlich PN, et al. Breast lymphoscintigraphy: high volume injection technique improves sentinel lymph node visualisation [abstract]. J Nucl Med. 1998;39(suppl):25p

24. Uren RF, Howman Giles RB, Thompson JF. Regarding sentinel lymph node localisation in early breast cancer [letter]. J Nucl Med. 1999;40:1403-1404.

25. Gulec SA, Moffat FL Jr, Krag DN. Regarding sentinel lymph node localisation in early breast cancer [reply to letter]. J Nucl Med. 1999;40:1404-1406.

26. Swartz MA, Berk DA, Jain RK. Transport in lymphatic capillaries. I. Macroscopic measurements using residence time distribution theory. Am J Physiol. 1996;270: H324-H329.

27. Krag DN, Ashikaga T, Harlow SP, Weaver DL. Development of sentinel node targeting technique in breast cancer patients. Breast J. 1998;4:67-74.

28. Berman C, Williamson M, Giuliano R, et al. Comparison of $2 \mathrm{cc}$ versus $6 \mathrm{cc}$ of radiopharmaceutical diluent in injections for breast lymphatic mapping [abstract]. Eur J Nucl Med. 1999;26(suppl):S66. 